\title{
EL PALACIO DE ESPAÑA EN ROMA A TRAVÉS DE LOS DIBUJOS DE FERDINANDO FUGA Y JOSÉ DE HERMOSILLA*
}

\author{
POR \\ Mercedes Simal LóPez \\ Museo Nacional de Artes Decorativas, Madrid
}

En 1747 se encargó al embajador español en Roma la realización de planos del palacio que albergaba la embajada, con el fin de estudiar si sería posible instalar en el edificio a los pensionados españoles que habían acudido a la ciudad bajo la protección de la Real Academia de Bellas Artes de San Fernando para completar su formación. Alfonso Clemente de Aróstegui encargó el trabajo al arquitecto Ferdinado Fuga, quien con la ayuda de uno de los alumnos de su estudio, José de Hermosilla, trazó seis planos del edificio. Recientemente localizados en el Archivo General de la Administración, constituyen un documento de enorme interés para el estudio de la sede diplomática y de la estancia italiana del pensionado español.

Palabras clave: Palacio de España en Roma; Ferdinando Fuga; José de Hermosilla; Alfonso Clemente de Aróstegui; Antonio Canevari; Troiano Acquaviva; Isabella de Acquaviva Strozzi; pensionados; Real Academia de Bellas Artes de San Fernando.

In 1747 the Spanish Ambassador in Rome was charged with the realization of plans of the building in which the Spanish Embassy was located for the purpose of studying wheter it would be possible to house the pensioners sent to the city by the Real Academia de Bellas Artes de San Fernando in order to complete their artistic studies. Alfonso Clemente de Aróstegui commissioned the architect Ferdinando Fuga to carry out the work, and assisted by one of his students, José de Hermosilla, they drew six plans of the building. Recently, these designs have been located in the Archivo General de la Administración; they constitute a document of enormous interest for the study of the diplomatic headquarters and for the Italian sojourn of the Spanish pensioner.

Key words: Palacio de España in Rome; Ferdinando Fuga; José de Hermosilla; Alfonso Clemente de Aróstegui; Antonio Canevari; Troiano Acquaviva; Isabella de Acquaviva Strozzi; pensioners; Real Academia de Bellas Artes de San Fernando.

\footnotetext{
* Quiero agradecer a Delfín Rodríguez Ruiz, Isabel Aguirre (Archivo General de Simancas) y Evelia Vega (Archivo General de la Administración), su ayuda y amabilidad mostrados durante la realización de este trabajo.
} 
"El diseño de n[uest]ro Palacio q[ue] me hizo Hermosilla en Roma, no me lo han devuelto los Reyes, y se lo tienen en la Sala de la Conversacion. Lo siento, y me complazco"1.

Con esta mal disimulada satisfacción Alfonso Clemente de Aróstegui, por entonces ministro plenipotenciario de la corona española en el Reino de las Dos Sicilias, informaba en 1753 de cómo Fernando VI y Bárbara de Braganza habían colocado en una de las estancias del Palacio del Buen Retiro los dibujos que, durante su etapa como embajador hispano ante la Santa Sede, había encargado realizar del palacio de España en Roma. Recientemente localizados en el Archivo General de la Administración de Alcalá de Henares, gracias a la minuciosidad con que fueron realizados y a que han conservado las leyendas explicativas que los acompañaban, nos han permitido conocer con exactitud el estado y la distribución del edificio en $1747^{2}$.

\section{El palacio de España en Roma: breve historia}

En un reciente trabajo hemos esbozado, brevemente, la historia de esta sede diplomática ${ }^{3}$, cara más visible de la presencia española en Roma junto a los diversos patronatos de fundación regia diseminados por la ciudad que, además de servir a sus funciones religiosas, se convirtieron en centros de celebración de festividades, rituales y ceremonias de exaltación de la monarquía hispánica.

Construido a finales del siglo XVI para Ascanio Iacobilli y su esposa, hija del embajador mediceo en Roma, el edificio fue adquirido para la Corona española en 1647 por el VIII conde de Oñate, logrando así que España fuera la primera potencia extranjera con embajada propia en Roma, gracias a la situación de privilegio de la que el reino de Felipe IV disfrutó bajo el pontificado de Inocencio $\mathrm{X}^{4}$. Tras la compra, don Íñigo Vélez de Guevara decidió remodelar el edificio,

\footnotetext{
${ }^{1}$ Carta de Clemente de Aróstegui, correspondencia reservada. s.f. [finales septiembre-comienzos de octubre de 1753]. Archivo General de Simancas, Estado (a partir de ahora AGS, E), leg. 5.857, doc. 75, citada en RodríGUEZ Ruiz, D., "De la utopía a la Academia. El Tratado de Arquitectura Civil de José de Hermosilla", Fragmentos, núm. 3, 1985 , p. 70.

2 En su libro sobre la historia de la sede de la embajada Alessandra Anselmi (Il Palazzo dell'Ambasciata di Spagna presso la Santa Sede, Roma, 2001, p. 113) daba noticia del proyecto de realización de planos del palacio encargados a Ferdinando Fuga, basándose en la copia de la documentación diplomática que se conserva en Roma del fondo Santa Sede del Ministerio de Asuntos Exteriores de Madrid (a partir de ahora MAE, SS.), leg. 310. Los planos y la documentación original del encargo a Fuga se conservan actualmente en el Archivo General de la Administración, Asuntos Exteriores (a partir de ahora AGA, AE), caja 54/261. Pero tenemos constancia de que antiguamente se encontraban en el legajo 5.101 de la sección Estado del AGS, tal y como consta en el tejuelo del siglo XVIII que refleja el contenido de la caja al inicio de la misma, aunque desconocemos los motivos del traslado de la documentación y en qué momento y circunstancias se produjo.

${ }^{3}$ Simal LóPez, M., "El Palacio de España en Roma, embajada hispana ante la Santa Sede, según Antonio Canevari (1726)”, Reales Sitios, núm. 162, 2004, pp. 72-74.

${ }^{4}$ A lo largo de la Edad Moderna los embajadores españoles aceptaron la "hospitalidad" de nobles y potentados, con las consiguientes contraprestaciones que ello conllevaba, o bien recurrieron al alquiler o compra de suntuosas residencias. Tan sólo sirva de ejemplo recordar que la embajada estuvo temporalmente instalada en el palacio Altemps a mediados del siglo XVI, en el Palacio Urbino durante el mandato de don Enrique de Guzmán, conde de Olivares (1582 y 1592), o en el Palacio Farnesio mientras que el marqués de Villena (1603-1606) conseguía alquilar el Palacio de Cupis en Piazza Navona, muy próximo a la iglesia de Santiago de los Españoles. Sobre este tema AlteA, C. de, Historia del Palacio de España en Roma, Madrid, 1972 y, sobre todo, Anselmi, A., ob. cit., 2001.
} 
encargando el proyecto a Francesco Borromini, quien centró su intervención en la reforma del vestíbulo y de la escalera, así como la articulación del patio y la reordenación de las distintas estancias del piano nobile ${ }^{5}$. Sin embargo, las obras tan sólo se llevaron a cabo parcialmente, al verse interrumpidas de forma brusca en 1648 debido al nombramiento del conde de Oñate como virrey de Nápoles, por lo que el palacio quedó "casi inabitable".

Durante la segunda mitad del siglo XVII tan sólo se practicaron en el edificio intervenciones de escasa entidad encaminadas a solucionar las distintas necesidades que planteaba el alojamiento de los embajadores y sus familias, así como a evitar su deterioro. Entre ellas destacaron las actuaciones llevadas a cabo por Antonio del Grande en $1654^{6}$ y Giovanni Domenico Pioselli entre 1696 y $1698^{7}$.

A comienzos del siglo XVIII el palacio presentaba un estado ruinoso, agravado sin duda por la falta de mantenimiento que había sufrido durante los años de la Guerra de Sucesión, ya que en 1709 la ruptura de relaciones diplomáticas entre Felipe V y la Santa Sede a causa del apoyo papal al candidato austriaco se tradujo en la expulsión de Roma del embajador y de los súbditos españoles que residían en la ciudad. Las relaciones entre ambos estados, tensas debido a la política regalista que habían desarrollado los distintos monarcas españoles, no se reanudaron hasta la firma del Concordato de 1717. En dicho año accede al cargo de embajador el cardenal Francesco Acquaviva $^{8}$, quien tras instalarse en la sede diplomática acometió importantes intervenciones, quedando a su muerte en 1725 el edificio totalmente remodelado 9 .

Su sucesor, el embajador interino Félix Cornejo, continuó con las mejoras del edificio, modificando algunas de las decoraciones al fresco patrocinadas por Acquaviva ${ }^{10} \mathrm{y}$ colocando escudos con las armas reales en la fachada del palacio y en el vestíbulo del piano nobile ${ }^{11}$. Además, en 1725 propuso ampliar el edificio adquiriendo varias casas contiguas, si bien el proyecto, encargado a Antonio Canevari, finalmente no se llegó a realizar ${ }^{12}$.

A partir de 1735 el puesto de embajador recayó en el cardenal Troiano Acquaviva, que también asumió el cargo de representante diplomático ante la Santa Sede del recién nombrado rey de las Dos Sicilias Carlos VII de Nápoles ${ }^{13}$. Definido como "el más gran señor de Roma [...] por su naturaleza magnífico", de "una alta y hermosa apostura" y que parecía "tener la

${ }_{5}^{5}$ Raspe, M. "Gli scaloni del Borromini: palazzo Pamphili, palazzo di Spagna, palazzo Barberini. Con un disegno del Cigoli per palazzo del Bufalo", en AA.VV., Francesco Borromini, Atti del convegno internazionale, Roma, 2000, pp. 107-121; y ANSELmi, A., ob. cit., 2001, pp. 54-76.

${ }^{6}$ Ante la necesidad de alojar convenientemente a la mujer del embajador y a sus damas, el edificio fue ampliado en dirección a la Via Mario de 'Fiori. Entre los objetivos del duque de Terranova también estaba el de remodelar la fachada de la embajada, proyecto que finalmente no se llevó a cabo. En relación a este tema, ANSELMI, A., ob. cit., 2001, pp. 79-86.

${ }^{7}$ MuÑoz GonZÁlez, M. J., "Algunos datos sobre el palacio de España en Roma y el patronazgo del conde de Altamira en su embajada", Archivo Español de Arte, núm. 292, 2000, pp. 408-415.

${ }^{8}$ Sobre su figura, véase Simal LóPez, M., "Acquaviva y Aragón, Francesco”, en Diccionario Biográfico Español, Real Academia de la Historia (en prensa). En relación a las fiestas que él y su sobrino, en calidad de embajadores, celebraron en Roma, Muniaín EDERRA, S., "Arquitectura efímera y diplomacia. Los Acquaviva y la imagen celebrativa de la Monarquía española ante la Santa Sede (1721-1746)", Reales Sitios, núm. 166, 2005, pp. 62-77.

${ }^{9}$ Las obras se llevaron a cabo bajo la dirección del arquitecto del cardenal Domenico Paradisi, y entre ellas destacaron la construcción de la capilla y la decoración al fresco de numerosas estancias del palacio por Placido Costanzi y Sebastiano Conca, quienes ya habían trabajado para Acquaviva en la decoración de la basílica de Santa Cecilia en Trastevere. Sobre este tema véase Anselmi, A., ob. cit., 2001, pp. 107-110 y VitTi, P., "Ferdinando Fuga e il nuovo ingresso alla chiesa di S. Cecilia in Trastevere”, Palladio, núm. 12, 1993, pp. 115-126.

${ }^{10}$ Algunas de las decoraciones al fresco aún se conservan bajo la tela que en la actualidad cubre las paredes de las distintas estancias del piano nobile. Agradezco la noticia a María del Carmen Clemente, quien amablemente me mostró las estancias de la embajada.

${ }_{11}$ Anselmi, A., ob. cit., 2001, p. 110

12 Simal López, M., ob. cit., 2004.

AEA, LXXXI, 321, ENERO-MARZO 2008, 31-48, ISSN: 0004-0428 
inteligencia como la estatura" 14 , además de continuar con la trayectoria de espléndido mecenas heredada de su tío Francesco, el intermediario de la correspondencia entre Benedicto XIV y Voltaire y protector de la Academia de Ciencias de Nápoles convirtió la embajada en lugar de reunión de artistas, viajeros e intelectuales ${ }^{15}$. Poseedor de una importante colección de obras de arte, repartida entre sus cuatro residencias romanas ${ }^{16}$, y miembro de la Academia de la Arcadia ${ }^{17}$, dentro sus actividades como embajador se encargó de "promocionar" a artistas italianos en la corte española, de informar a los monarcas de las principales obras de arte que estaban a la venta en la ciudad ${ }^{18}$, y de llevar a cabo proyectos de exaltación de la casa Farnesio tales como la espléndida edición ilustrada por Giuseppe Vasi de las pinturas que decoraban el palacio Farnesio de Caprarola ${ }^{19}$.

En lo que respecta a la embajada, durante su etapa como ministro plenipotenciario ante la Santa Sede continuó con las mejoras del edificio, amueblado magníficamente con piezas de su propiedad $^{20}$. Además de reparar los daños causados en el palacio por el incendio del archivo en enero de 1738, con permiso del rey llevó a cabo distintas intervenciones con el objetivo de "evitar su ruina" 21 y a partir de 1744 se decoraron al fresco distintas salas del piano nobile, entre las que destacaba el salón de audiencia, en el que trabajó el caballero Marco Benefial, y la construcción de un nuevo teatro ${ }^{22}$.

${ }^{13}$ Nicolini, F., "Troiano Acquaviva d'Aragona", en Dizionario biografico degli italiani, Roma, 1960, Vol. I, pp. 198-199; Idem, "Un dimenticato personaggio casanoviano. Il Cardinale Troiano Acquaviva", Banco di Napoli. Biblioteca del "Bollettino dell'Archivio Storico", IX, 1964, pp. 5-39; OzAnam, D., Les diplomates espagnols du XVIII siècle, Madrid-Burdeos, 1998.

14 De Brosses, P., Viaje a Italia, Madrid, 1923, Vol. III, pp. 26-27.

15 "La tertulia del cardenal Acquaviva [...] se celebra dos veces por semana; es numerosa y magnífica; no se juega más que rara vez. Es una tertulia propiamente dicha, puesto que no se hace mas que charlar en corrillos y yendo y viniendo por los salones; a veces hay música, y siempre abundancia de chocolate y agua helada" (DE BRosses, P. de, ob. cit., Vol. III, p. 26). Asimismo Giambattista Vico definió la embajada durante la época de Acquaviva como "sempre aperta ad uomini chiari per valor di lettere, che riceve con umanità singolare e protegge con incredibile fortezza e promueve con alta generosità" (ANSELMI, A., ob. cit., 2001, p. 112).

${ }^{16}$ El Palacio de España en Roma era una de las residencias en las que Acquaviva habitaba a lo largo del año, junto con el Casino Farnese próximo a la Puerta de San Pancracio en Roma, el palacio Farnesio de Caprarola y el Palacio de la Abadía de San Paolo en Albano. En ellas se distribuían las 1653 obras que componían su colección, entre las cuales se encontraban pinturas de Rubens, Conca, Trevisani, Bonito, Luca Giordano, Durero y Maratta, que actualmente se encuentran repartidas por distintos museos europeos. AscenzI, V., "Trojano Acquaviva d'Aragona, un cardinale collezionista d'arte a Roma", Studi di storia dell'arte, núm. 13, 2002, pp. 265-269.

${ }^{17}$ Fue nombrado "Arcade acclamato" en 1742, tomando el nombre de Troilo. GiorgietTi Vichi, A. M., Gli arcadi dal 1690 al 1800, Onomasticon, Roma, 1977.

18 Atento observador del mercado artístico romano, con la intención de incrementar la colección real española informó en 1735 a Felipe V e Isabel de Farnesio de la puesta a la venta de interesantes colecciones de obras de arte en la ciudad, entre las que destacaban la de pinturas de la familia Sacchetti y la de esculturas de la princesa del Piombino. Sobre este tema, Simal LÓPEZ, M., "Isabel de Farnesio y la colección real española de escultura. Distintas noticias sobre compras, regalos, restauraciones y el encargo del "Cuaderno de Ajello", Archivo Español de Arte, núm. 315, 2006, p. 269.

19 Illustri fatti Farnesiani coloriti nel Real Palazzo di Caprarola dai fratelli Tadeo Federico e Ottaviano Zuccar [...], Roma, 1748 [Real Biblioteca de Palacio (a partir de ahora RBP), IX-M-117].

${ }^{20}$ En 1735, con motivo de la promoción al título de Cardenal del infante don Luis, se celebró una función pública en la embajada, "estando todos los cuartos de este R[ea] $]^{1}$ Palacio guarnecidos de ricos quadros, y de colgaduras galoneadas de oro, y de un gran numero de arañas de christal, y placas llenas de luces, que no se distinguia si era de día, o de noche". AGS, E, leg. 4.893.

${ }^{21}$ Carta de T. Acquaviva a Villarias. Roma, 8 de octubre de 1739, AGS, E, leg. 4.909.

22 Respecto a las decoraciones llevadas a cabo en el piano nobile, en las cuentas de gastos figuran pagos en 1744 a Marco Benefial, miembro de la Accademia di San Luca y de la Arcadia, por decorar "con diversas figuras" la bóveda 


\section{Clemente de Aróstegui, ministro interino ante la Santa Sede}

Tras la muerte del cardenal en marzo de 1747 tomó el relevo al frente de la embajada el jurista Alfonso Clemente de Aróstegui, que hasta entonces había ocupado el cargo de Auditor de la Rota $^{23}$. A pesar de la brevedad de su mandato en calidad de ministro interino-comprendido entre marzo de 1747 y noviembre de 1748- emprendió numerosas iniciativas destinadas a mejorar los servicios que la embajada prestaba a los súbditos de la Corona española.

También miembro de la Academia de la Arcadia $^{24}$ y con interés e inquietud hacia las bellas $\operatorname{artes}^{25}$, Clemente de Aróstegui se había ocupado desde su llegada a Roma en 1744 de los pensionados españoles trasladados a la ciudad para completar su formación, siguiendo el modelo de la Academia Francesa fundada en la Ciudad Eterna por Luis XIV ${ }^{26}$.

En 1747 el número de "becarios" españoles en Roma, que constituían la primera promoción, ascendía a un total de seis. Las pensiones habían sido concedidas a dos artistas que ya se encontraban en la ciudad, el pintor Francisco Preciado de la Vega y el escultor Francisco Vergara, mientras que las restantes fueron designadas por oposición. Si bien el proceso fue complicado y presentó numerosas arbitrariedades, en el caso de los arquitectos ninguno de los ganadores llegó finalmente a viajar a Roma. En su lugar lo hicieron Miguel Fernández, que quedó como suplente y ocupó la plaza de Alejandro González Velázquez, y José de Hermosilla, delineador del Nuevo Palacio Real, a quien Fernando VI adjudicó el 2 de mayo de 1747 la plaza de Diego de Villanueva ${ }^{27}$.

de la "Sala Regia" y por realizar, junto a Juan Baptista Olivieri, pinturas "en quatro salas del Real Palacio". Asimismo, en 1745 se pagaron 150 escudos a Jacome Rubini por la pintura hecha en la bóveda "de la Sala Grande del Real Palacio" (AGS, E, leg. 5.136). En relación a la construcción del teatro, el marqués del Carpio había adquirido en 1682 la estructura de madera del Teatro Capranica para instalarla en la embajada, si bien fue desmontada y trasladada a Nápoles cuando se le concedió el puesto de virrey (ANSELmi, A., ob. cit., 2001, p. 88). Posteriormente, durante la primera mitad del siglo XVIII, los distintos embajadores españoles alquilaron varios palcos y estancias en los principales teatros de la ciudad, pero ante las dificultades que surgieron para arrendarlos a partir de $1735 \mathrm{y}$ la imposibilidad de colocar escudos en ellos (AGS, E, leg. 4.894), Troiano Acquaviva decidió en 1745 la construcción de uno propio en la misma sede diplomática. El encargado de realizarlo fue el carpintero Sebastián Moroni, ocupándose de su decoración Felipe de Castro y el pintor Juan Baptista Olivieri (AGS, E, leg. 5.136). Una vez inaugurado, en él actuaron "los primeros músicos de esta corte acompañados de los mas excelentes instrumentos de la misma, q[ue]. entre clarines, violines, y clavicordios excedian el n. ${ }^{\circ}$ de 150" (AGS, E, leg. 4.893).

${ }^{23}$ Sobre su biografía y sus obras, Rezabal y Ugarte, J. de, Biblioteca de los escritores que han sido individuos de los seis colegios mayores: de San Ildefonso de la Universidad de Alcalá, de Santa Cruz de la de Valladolid, de San Bartolomé, de Cuenca, San Salvador de Oviedo, y el arzobispo de la de Salamanca, Madrid, 1805, pp. 74-80 y OZANAM, D., ob. cit., p. 232.

${ }^{24} \mathrm{Su}$ nombre arcade era Florisbo Aganippeo. Giorgietti Vichi, A. M., ob. cit.

25 Durante su etapa como embajador hispano en el Reino de las Dos Sicilias, Clemente de Aróstegui se encargó de informar a Carlos III de la evolución de las obras del palacio de Caserta y de las excavaciones de Herculano, y entre otras gestiones fue el responsable del traslado de Corrado Giaquinto a la corte española para sustituir al fallecido Amigoni. Sobre este tema, URREA FernáNDEZ, J., Relaciones artísticas hispano-romanas en el siglo XVIII, Madrid, 2006, pp. 27-37.

${ }^{26}$ Urrea, J., "Pintores españoles en Roma a mediados del siglo XVIII", Boletín del Museo e Instituto "Camón Aznar”, LXXV-LXXVI, 1999, pp. 366-386.

27 Respecto al primer turno de pensionados de arquitectura véase BÉDAT, C., La Real Academia de Bellas Artes de San Fernando (1744-1808), Madrid, 1989, pp. 249-252; QuintanA MarTíneZ, A., La arquitectura y los arquitectos en la Real Academia de Bellas Artes de San Fernando (1744-1774), Madrid, 1983, pp. 93-94; Moleón, P., "Arquitectos españoles en Roma durante la segunda mitad del siglo XVIII", Reales Sitios, núm. 152, 2002, pp. 49-51; Idem, "Arquitectos españoles en Roma durante la segunda mitad del siglo XVIII", Reales Sitios, núm. 152, 2002, pp. 49-51; MoleÓn, P., Arquitectos españoles en la Roma del "Grand Tour”. 1746-1796, Madrid, 2003, pp. 105-153; GARCía SÁNCHEZ, J., El valor de la Antigüedad en la formación de los arquitectos españoles pensionados en Roma (siglos XVIII y XIX), Tesis Doctoral inédita, U.C.M., 2005, cap. 2. 
Con el dinero concedido por la Academia los pensionados debían cubrir sus gastos de alojamiento, ya que no disponían de un lugar de residencia establecido ${ }^{28}$. Respecto a su programa de aprendizaje y trabajo, al no existir durante los primeros años la figura de director, se encargó de su formación y tutela el propio embajador Clemente de Aróstegui. El futuro viceprotector de la Academia en Madrid fue el responsable de ponerles a cargo de los grandes maestros de las respectivas artes, como hizo al colocar a Hermosilla bajo las enseñanzas de Ferdinando Fuga y a Miguel Fernández con Luigi Vanvitellii ${ }^{29}$. Del mismo modo, semanalmente les reunía en su residencia para observar cómo trabajaban, y se encargaba de hacer llegar a Madrid las obras que los pensionados estaban obligados a realizar para que los académicos juzgaran su evolución y aprovechamiento ${ }^{30}$.

\section{La embajada de España ante la Santa Sede durante el mandado de Clemente de Aróstegui: proyectos y diseños}

En lo que respecta al palacio de España en Roma, sabemos que nada más tomar posesión del cargo, el 30 de marzo de 1747 Clemente de Aróstegui envió a Joseph de Carvajal un detallado informe del estado en que se encontraba la sede diplomática, acompañado de varias propuestas relativas a su decoro y mantenimiento ${ }^{31}$.

Si bien el edificio se hallaba en buenas condiciones constructivas gracias a las importantes remodelaciones que había efectuado Troiano Acquaviva, en lo que respecta a su decoración las salas de representación del piano nobile iban a quedar en poco tiempo vacías a causa de la costumbre por la cual los embajadores debían ocuparse de alhajarlo a sus expensas ${ }^{32}$. Clemente de Aróstegui solicitó al Secretario de Estado reparar esta situación de inmediato, adquiriendo con fondos de la Corona parte de los bienes del cardenal Acquaviva que habían "vestido con la mayor ostentación, y magnificencia" la embajada, antes de que fueran retirados por sus herederos $^{33}$. Asimismo proponía utilizar, si fuese preciso, los trabajos de los pensionado de la Academia para decorar las estancias de la embajada, lo cual "seria en el genio de esta corte cosa de mucho lustre, sin gasto a la R[ea $]^{1}$ hacienda". Para concluir su informe el nuevo embajador describió el buen estado que presentaban distintas dependencias de la sede diplomática, entre las que destacaban la capilla, la secretaría, el archivo -calificado como "una de las mejores cosas que el Rey tenia, y no le tenia otro Príncipe igual” en Roma-, la contaduría, la sala donde se encontraba la imprenta - muy útil "en los casos necessarios de imprimir lo que ocurriesse con fidelidad y secreto"- y la armería.

${ }^{28}$ En los estatutos redactados en 1757 se planteaba instalar a los pensionados en el hospital de Santiago de los Españoles, si bien finalmente no se llevó a cabo por la falta de espacio. LóPEZ DE MENESES, A., "Las pensiones que en 1758 concedió la Academia de San Fernando para ampliación de estudios en Roma", Boletín de la Sociedad Española de Excursiones, 1933, pp. 253-300.

${ }^{29}$ Moleón, P., ob. cit., 2003, p. 86.

${ }^{30}$ Quintana MartíneZ, A., ob. cit., pp. 95-96.

31 AGA, AE, caja 54/261.

32 Tan sólo conocemos el modo en que estaba decorado el palacio en la época del marqués del Carpio gracias a su inventario de bienes redactado en 1682 (Archivo de los duques de Alba, caja 302, núm. 4, trascrito parcialmente en Burke, M. y Cherry, P., Collections of Paintings in Madrid, 1601-1755, Los Ángeles, 1997, pp. 729-762). Sobre este tema véase también De Frutos SAstre, L., El VII marqués del Carpio (1629-1687). Mecenas y coleccionsta de las artes, Tesis Doctoral inédita, UCM, 2006.

${ }^{33}$ No fue hasta la marcha del embajador Manuel de Roda en 1766 cuando la Corona decidió adquirir el mobiliario y los bienes del diplomático para alhajar la embajada hispana ante la Santa Sede de modo permanente. De esa fecha data un minucioso inventario realizado por estancias (AGS, E, libro 203). 
Desde la corte madrileña se aprobó la propuesta de Aróstegui de que los trabajos de los pensionados de escultura y pintura adornasen las estancias del palacio "si eran dignos", pero con respecto a la idea de gravar al tesoro real con los gastos de "alhajar el palacio con bienes muebles propios", Fernando VI condicionó la decisión a que "las urgencias de la Corona dejasen libertad para expender caudales en otros destinos que los de la Guerra, y de las cargas de justicia"34.

El secretario de Estado también solicitó al embajador que estudiase si en el edificio de la sede diplomática, "y sin que sirva de incomodidad, de indecoro, ni de sugecion, se podrán segregar, y destinar las piezas que sean precisas para la Academia y Académicos que fueran de acá a sueldo del Rey"35, recuperando la propuesta que en el pasado había hecho el marqués del Carpio ${ }^{36}$. En el mes de junio Joseph Carvajal concretó aún más su petición, solicitando al embajador planos detallados del edificio para que en Madrid tuvieran "perfecta noticia de lo que es essa cassa en su extension, y en su distribucion" y de la zona franca que rodeaba la embajada ${ }^{37}$, cuya validez había sido puesta en duda por el Pontífice tras la muerte de Acquaviva ${ }^{38}$.

La respuesta de Clemente de Aróstegui no se hizo esperar. Al mes siguiente enviaba a Carvajal el plano de la zona bajo jurisdicción de la embajada, y le informaba de que "se estan tomando ya las medidas de este Palacio por el arquitecto Cavallero Fuga, a quien he dado la comision, respecto de ser este de quien se servia el difunto Card[ena $]^{1}$ de Acquaviva" 39 . La relación entre ambos, de carácter profesional y de $\operatorname{amistad}^{40}$, había comenzado en 1730 con el nombramiento del florentino como arquitecto de los Palacios Apostólicos. Desde esa fecha hasta 1732 Fuga trabajó en directa colaboración con Acquaviva, quien desde 1729 ocupaba el cargo de Maggiordomo dei Sacri Palazzi, entre cuyas funciones se encontraba la de supervisar las intervenciones arquitectónicas que se realizaran en los edificios apostólicos ${ }^{41}$.

${ }^{34}$ Carta de Joseph de Carvajal a Alfonso Clemente de Aróstegui, Aranjuez, 2 de mayo de 1747. MAE, S. S., leg. 196, doc. 26 .

35 Sobre la problemática de la búsqueda de sede para la Academia española en Roma, Moleón, P., ob. cit., 2003, pp. 82-83.

36 Pérez Bueno, "De la creación de una academia de arte en Roma. Año 1680", Archivo Español de Arte. 1947, pp. 155-157; SÁnchez CAnTón, F. J., "Nota acerca de la creación de una Academia de Arte en Roma. Año 1680", Archivo Español de Arte. 1947, p. 255.

37 El barrio en el que estaba instalada la embajada gozaba de un régimen jurisdiccional de excepción que databa de 1635, cuando el marqués de Castel Rodrigo consiguió el compromiso por parte de las autoridades pontificias de respetar la inmunidad de la plaza y los contornos de la embajada y de no efectuar detenciones. Asimismo, la embajada contaba con una milicia propia acuartelada en el palacio, que en ocasiones era reforzada con tropas procedentes del reino de Nápoles, mientras que el resto de sedes diplomáticas extranjeras en Roma tan sólo disponían de pequeñas guardias de soldados para acompañamiento y pompa del embajador, pero sin jurisdicción sobre las inmediaciones de su sede diplomática. Sobre este tema véase Anselmi, A., "El marqués del Carpio y el barrio de la embajada de España en Roma (1677-1683)", en La monarquía de las naciones. Patria, nación y naturaleza en la Monarquía de España (Actas del Congreso, Fundación Carlos de Amberes, 17-19 de diciembre de 2003), Madrid, 2004, pp. 559-589.

${ }_{38}$ Carta de Joseph de Carvajal y Lancaster a Alfonso Clemente de Aróstegui, Aranjuez, 20 de junio de 1747. MAE, SS, leg. 196, doc. 46.

39 AGA, AE, caja 54/261.

40 En 1738 el cardenal actuó como padrino en el bautismo de la hija del arquitecto. ANTINORI, A., "Note su Troiano Acquaviva d'Aragona protoilluminista e committente di Ferdinando Fuga”, Studi sul Settecento napoletano, núm. 2, 2001, p. 118

${ }_{41}$ Bajo la dirección de Acquaviva Fuga completó el edificio delle scuderie, el palacio delle Cifre, y remodeló el palacio del Quirinal. Sobre la obra del arquitecto véase PANe, R., Ferdinando Fuga, Nápoles, 1956; PorTogheSSI, P., Roma barocca, Roma, 2001, pp. 471-486; KIEVEn, E., Ferdinando Fuga e l'architettura romana del Settecento. I disegni di architettura dalle collezioni del Gabineto Nazionale delle stampe. Il Settecento, Roma, 1988; Idem, "Ferdinando Fuga (1699-1781)", en Curcio, G. y Kieven, E., Storia dell'architettura italiana. Il Settecento, Milán, 2000, pp. 540-555; y los distintos estudios recogidos en Studi sul Settecento napoletano, núm. 2, 2001.

AEA, LXXXI, 321, ENERO-MARZO 2008, 31-48, ISSN: 0004-0428 
Ya en calidad de embajador de España y del Reino de las Dos Sicilias ante la Santa Sede, Troiano Acquaviva propuso a Fuga como sustituto de Juvarra para dirigir las obras del Palacio Real de Madrid en $1736^{42}$, pero ante la imposibilidad de que se desplazara a España al no haber obtenido permiso papal, le nombró arquitecto de los "Reali Effetti Farnesiani a Roma" y de la iglesia de Santiago de los Españoles ${ }^{43}$. Del mismo modo Fuga también fue designado por el cardenal para diseñar distintas arquitecturas y decoraciones efímeras erigidas en Roma con motivo del matrimonio de Carlos VII de Nápoles con María Amalia de Sajonia (1738), del enlace del infante don Felipe con la hija de Luis XV de Francia (1739) y para las exequias de Felipe V (1746). También le hizo participar, en calidad de académico de San Luca, en el "arbitraje" de los proyectos de Sacchetti para la capilla (1741-1742) y la escalera (1746) del Palacio Real nuevo de Madrid ${ }^{44}$, y ya en el ámbito de lo privado Acquaviva le encargó en 1741 la remodelación del ingreso al convento y basílica de Santa Cecilia en el Trastevere, del que el cardenal era protector y titular, y en donde estaban sepultados distintos miembros de la familia Acquaviva ${ }^{45}$.

\section{El encargo de los planos de la embajada en 1747}

Volviendo sobre la tarea encomendada a Clemente de Aróstegui, el primer plano que el embajador envió a Madrid fue un diseño del "cuartel" español, si bien éste fue devuelto a Roma para que se aclarasen los límites de la zona franca y se marcasen las zonas en las que había habido conflictos con la autoridad pontificia, especialmente numerosos durante la embajada de Troiano Acquaviva (fig. 1) ${ }^{46}$. Clemente de Aróstegui remitió en agosto un nuevo diseño, en el que iba marcado en negro la zona comprendida en el franco de la embajada y en amarillo los límites de

42 Tras la negativa de Antonio Canevari, Felipe V consultó a Acquaviva si en Roma "hay persona capaz de tal encargo", a lo que el cardenal respondió que "como le tengo avisado, entre los arquitectos que se hallan en esta corte, el mas a proposito para suplir la falta del expresado Juvarra, me parece el cavallero Fuga de nación toscano, el qual creo desempeñará su obligación en el R[ea] ${ }^{1}$ Servicio, haviendo hecho aquí diversas fábricas de consideración con universal aplauso y aprobación" (Roma, 3 de mayo de 1736, carta de Acquaviva a Joseph Patiño, AGS, E, leg. 5.806, fol. 53). Se llegó a librar dinero para el viaje del florentino (Roma, 12 de junio de 1736, Idem, fol. 57), pero finalmente la falta de permiso papal impidió que ocupara el puesto. En relación con este tema, sobre el que hay abundante bibliografía, sigue siendo fundamental PlazA, F. J. de la, Investigaciones sobre el Palacio Real nuevo de Madrid, Valladolid, 1975, p. 21.

43 Sobre Fuga y la iglesia de Santiago véase D’Antonio, P., "Ferdinando Fuga architetto della corte borbonica", Studi sul Settecento napoletano, núm. 2, 2001, p. 305; SARAceni, M. L., "La casa di Ferdinando Fuga per la congregazione di S. Giacomo degli Spagnoli", Studi sul Settecento Romano, núm. 10, 1994, pp. 305-314; Idem, "L'attività di Ferdinando Fuga per l'edilizia residenziale", Studi sul Settecento Romano, núm. 14, 1998, pp. 201-215.

44 Respecto a la crítica romana a los distintos proyectos realizados en Madrid, SANCHO GaSPAR, J. L., "El Palacio Real de Madrid, alternativas y críticas a un proyecto", Reales Sitios, núm. extraordinario, 1989, pp. 167-180; Idem, "Las críticas en España y desde Italia al Palacio Real de Madrid: Fuga, Salvi y Vanvitelli”, Archivo Español de Arte, núm. 254, 1991, pp. 153-169; Idem, "Ferdinando Fuga, Nicola Salvi y Luigi Vanvitelli; el Palacio Real de Madrid y sus escaleras principales", Storia dell'Arte, núm. 72, 1991, pp. 199-252; RodRÍGUEZ RuIZ, D. "El Palacio Real de Madrid", en Rodríguez Ruiz, D. (ed.), Palacios Reales en España. Historia y arquitectura de la magnificencia, Madrid, 1996, pp. 153-180.

45 VITTI, P., ob. cit.

46 Tan sólo a modo de ejemplo mencionar un completo registro de las agresiones llevadas a cabo por los soldados españoles entre 1742 y 1745 (Archivo Secreto Vaticano, Archivo de la Nunciatura, Madrid, Vol. 91, fols. 36-47) o el esbozo que se envió en 1748 a la secretaría de Estado para explicar al embajador el conflicto que había tenido lugar entre la guardia del palacio de España y los aclamadores del Gran Duque en 1745 (AGA, AE, planeros, caja 54/261, doc. 5, plano 13) (il. 1). 


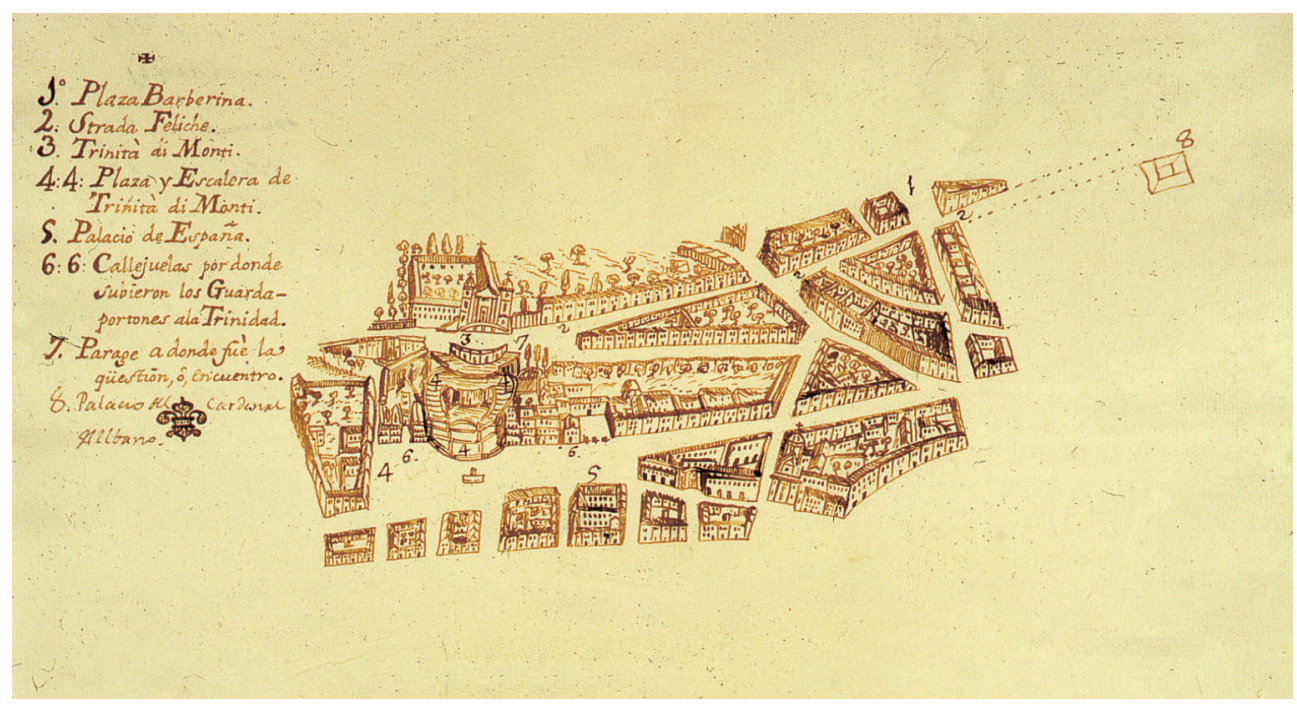

Fig. 1. Anónimo, Esbozo del "cuartel” de la embajada de España en Roma realizado con motivo de los incidentes registrados entre la guardia española y los aclamadores del Gran Duque, 1748. Archivo General de la Administración.

la jurisdicción hispana (fig. 2), dentro de la que se incluían la escalinata que conducía a la iglesia de patronato francés de Trinitá dei Monti y el colegio de Propaganda Fide ${ }^{47}$.

Meses más tarde, el 9 de noviembre de 1747, Aróstegui mandó a Madrid el "diseño de la fachada de este palacio; su espacato, con quatro plantas de sus quatro planos, con toda su distribucion, y el indice o sea explicacion de cada plano hecho por el arquitecto, y ademas algunas advertencias mias", acompañados de un memorial en el que informaba cumplidamente de las distintas cuestiones planteadas desde Madrid ${ }^{48}$.

En relación a "si habria lugar en este Palacio para la Academia de las tres Artes", Clemente de Aróstegui respondió negativamente, considerando que "si se tratasse el poner la Academia con toda su formalidad, como la tiene el Rey de Francia, no se podria executar sin grande incomodidad, y sin gasto; pero si se tratasse solo de poner tal qual orden en los seis pensionados con reducirlos a vivir en el Palacio, con la direccion, que haze tiempo tengo ya insinuada, se podria a lo menos por ahora executar, dandoles habitaciones, y una pieza comun para modelos, y estudio". A continuación el embajador procedió a realizar un interesante comentario de los planos que, junto con las leyendas indicando el uso de las distintas estancias, redactadas por los arquitectos en castellano e italiano, constituyen un valioso documento para el conocimiento de la embajada ${ }^{49}$.

Definida como uno de los mejores palacios de Roma, Aróstegui puntualizaba que el edificio podría ser "por fuera mas magnifico" si se agregasen al Palacio varios solares con el fin de

${ }^{47}$ AGA, AA.EE., caja 54/261, planeros, documento 5, plano 12. El 19 de septiembre Joseph de Carvajal notificaba a Clemente de Aróstegui la recepción del plano (MAE, SS, leg. 196, doc. 94).

${ }^{48}$ Los planos y la documentación del encargo y envío a la corte madrileña se conservan actualmente en el AGA, AE, caja 54/261. Los dibujos del palacio (AGA, AE, caja 54/261, planeros, documento 1, planos 1-6) están realizados en papel verjurado con filigrana del tipo "Lirio de Estrasburgo", a escala de 200 palmos romanos. Por el contrario, el plano del "cuartel" (AGA, AE, caja 54/261, planeros, documento 5, plano 12) está realizado sobre un papel más grueso con filigrana en forma de "P" y carece de escala.

49 AGA, AE, caja 54/261. 


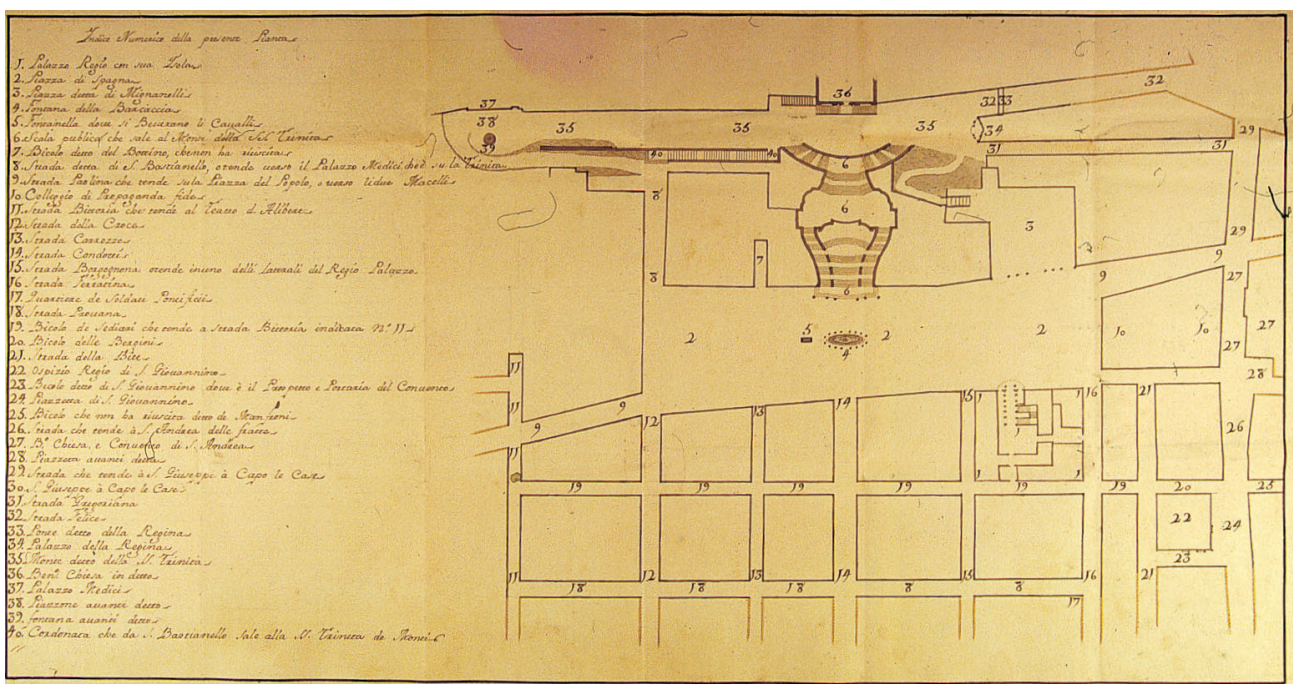

Fig. 2. Anónimo, Plano del "cuartel" de la embajada de España en Roma, 1743. Archivo General de la Administración.

uniformar la fachada y poder instalar así en la planta baja -aunque de manera independiente a la sede diplomática- la oficina de correos y el banco regio ${ }^{50}$. A pesar de que se envió a Madrid un detallado informe con la tasación de dichas casas, realizado por Fuga, el proyecto no llegó a llevarse a cabo. Aún en la actualidad, en la embajada se sigue planteando un problema de espacio idéntico que requeriría una solución similar.

Respecto al plano de la planta baja (fig. 3$)^{51}$-donde se ubicaban las caballerizas y numerosas dependencias de servicio como cocinas, almacenes, estancias para la guardia, etcétera- tan

${ }^{50}$ Acerca de la fundación de esta oficina bancaria en Roma, subalterna del Banco Real de Madrid, con el fin de agilizar el cobro de rentas y de pensiones eclesiásticas en Italia reduciendo los gastos y el tiempo de espera, véase AGS, E, leg. 5.067.

${ }^{51}$ AGA, AE, planeros, caja 54/261, documento 1, plano 3. Transcripción de la leyenda: "Indice de esta planta, que es el quarto vajo del Real Palacio de España q[u] está en Roma. N. ${ }^{\circ}$ I. 1. Entrada principal del zaguan cubierto. 2. Patio principal con fuente al testero. 3. Escalera principal. 4. Entrada devajo de la escalera pr[incip]âl $\mathrm{q}[\mathrm{u}]^{\mathrm{e}}$ conduce a las siguientes oficinas, y a otras comodidades. 5. Cocina grande. 6. Ramillete. 7. Cocina secreta, con escalera $\mathrm{q}[\mathrm{u}]^{\mathrm{e}}$ conduce a los entresuelos de encima. 8. Pieza donde se tienen, o guardan los bancos p[ar]. ${ }^{a}$ las serenatas. 9. Entrada a las carboneras. 10. Carboneras. 11. Pieza donde se guardan materiales, y herramientas de albañil. 12. Pieza para el espostillero. 13. Pieza de la guardia de los soldados. 14. Cuatro piezas libres $\mathrm{p}[\mathrm{ar}]{ }^{\mathrm{a}}$ despensa, y otros usos. 15. Escalerilla $\mathrm{q}[\mathrm{u}]^{\mathrm{e}}$ antes servía a los entresuelos superiores, con puerta secreta $\mathrm{q}[\mathrm{u}]^{\mathrm{e}}$ corresponde a la calle Borgoñona. 16. Escalerilla $\mathrm{q}[\mathrm{u}]^{\mathrm{e}}$ conduce a los entresuelos superiores. 17. Pieza para el picador. 18. Dos piezas libres para diversos usos. 19. Pieza para los correos devajo de la qual está la cocina comun. 20. Otra carbonera $\mathrm{p}[\mathrm{ar}] .{ }^{\mathrm{a}}$ servir a d[ic]ha cocina. 21. Cochera con comunicación al patio. 22. Otras dos cocheras $q^{e}$ corresponden al patio. 23. Guadarnes. 24. Passo q[u] comunica al siguiente patio. 25. Segundo patio, $\mathrm{q}[\mathrm{u}]^{\mathrm{e}}$ corresponde con portada a la calle Fratina. 26. Despensa para servidumbre de la cocina grande. 27. Dos cocheras que corresponden a dho seg[un]do patio. 28. Dos piezas para diversos usos. 29. Lugares comunes publicos. 30. Tienda o obrador, con una pieza detrás, corredor, y escalera $\mathrm{q}[\mathrm{u}]^{\mathrm{e}}$ conduce al plano superior para uso del Armero del R[ea] ${ }^{1}$ Palacio. 31. Cavalleriza, de cavallos de regalo, devajo de la qual ay otra, llamada el Gruton, la qual tiene la entrada $\mathrm{p}[\mathrm{o}]^{\mathrm{r}}$ la calle Borgoñona. 32. Corredor el qual tiene la entrada de la dha cavalleriza, y del patio y conduce a algunos entresuelos $\mathrm{q}[\mathrm{u}]^{\mathrm{e}}$ ay sobre los siguientes cuerpos. 33. Escalera secreta. 34. Pasillo que de d[ic]ha escalera secreta conduce a la calle Borgoñona. 35. Vajo escalera. 36. Dos cocheras q[u $]^{\mathrm{e}}$ corresponden

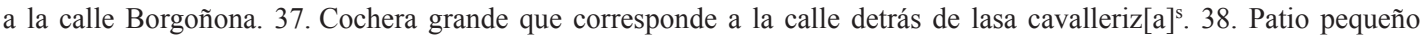


Fig 3. Ferdinando Fuga y José de Hermosilla, N. I. Pianta del Piano Terreno del Reggio Palazzo di Spagna esistente in Roma, 1747. Archivo

General de la Administración.

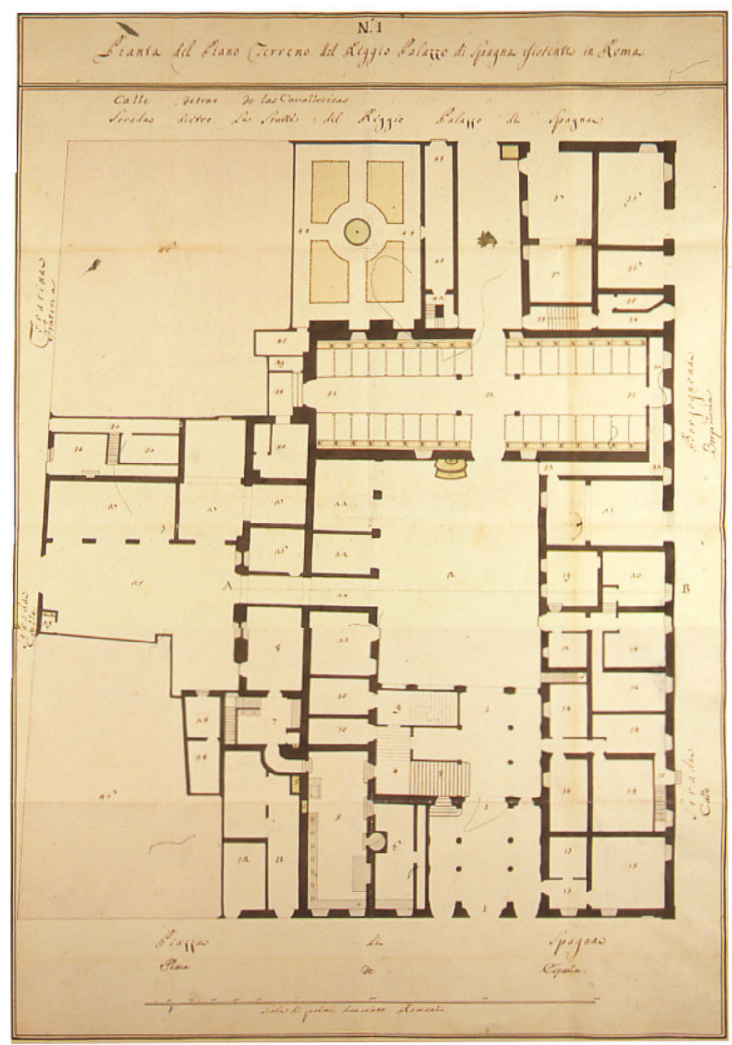

sólo presenta pequeñas modificaciones respecto a los diseños realizados en 1726 por Antonio Canevari, tales como la compartimentación del jardín en pequeños parterres, o la eliminación de las columnas que enmarcaban la fuente del cortile grande ${ }^{52}$. Aunque había varias estancias vacías que anteriormente habían sido utilizadas para guardar las carrozas del cardenal Acquaviva (núms. 21, 36 y 37), no se podían destinar para habitación de los pensionados debido a su poca salubridad.

En el Prospetto della Facciata Principale (fig. 4) se habían excluido las casas anejas a la embajada que se querían adquirir para ampliar el edificio y unificar la fachada. Como un palimpsesto, el estado que ofrecía en 1747 era el resultado de numerosas intervenciones arquitectónicas y decorativas, entre las que destacaban el orden rústico de la entrada diseñada por Borromini, o el escudo de mármol con las armas del rey obra de Canevari. En la representación, se suprimieron también los dos grandes escudos con las armas del rey de España y del Pontífice

para uso de d[ic]ha cavalleriza. 39. Pieza para la zevada. 40. Pieza con un quartito para uso de tener el heno (diario) $\mathrm{p}[\mathrm{ar}]{ }^{\mathrm{a}}$ la cavalleriza. 41. Patio pequeño con pozo, y puertagrande, $\mathrm{q}[\mathrm{u}]^{\mathrm{e}}$ de la cavalleriza sale a la calle, detras de las cavallerizas. 42 . Escalera secreta para uso solam[en $]^{\text {te }}$ del quarto principal, y conduce al referido patio pequeño, y al siguiente corredor. 43. Corredor con puerta secreta $\mathrm{q}[\mathrm{u}]^{\mathrm{e}}$ corresponde a la calle detras de las cavallerizas, y conduce tambien al siguiente jardin. 44. Jardin secreto con fuente en medio. 45. Piezezita $\mathrm{p}$ [ar]. ${ }^{\mathrm{a}}$ guardar los naranjos y tiestos de d[ic]ho jardin. 46. Sitios coloridos de rojo en donde estan diversas casas que son de varios dueños, $\mathrm{q}[\mathrm{u}]^{\mathrm{e}}$ unidos al cuerpo del R[ea] $]^{1}$ Palacio constituien la planta de toda la isla, y queda el mismo como de la planta se reconoce".

52 Se conservan dos ejemplares en AGS, M. P. y D., III-28, y Museo Naval, Sección de Cartografía, plano 24-1. 


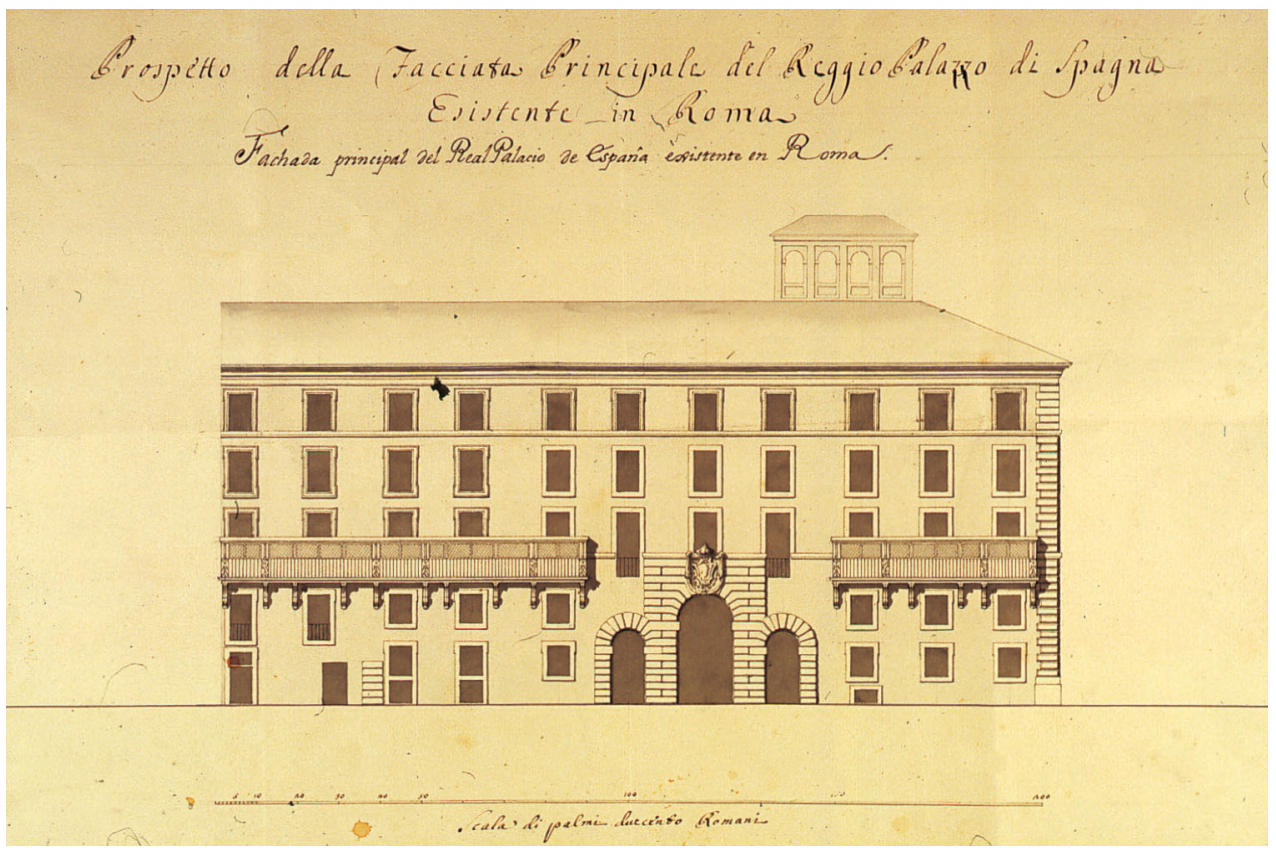

Fig. 4. Ferdinando Fuga y José de Hermosilla, Prospetto della Facciata Principale del Reggio Palazzo di Spagna esistente in Roma, 1747. Archivo General de la Administración.

colocados en la parte superior de la fachada, probablemente retirados por los conflictos que el embajador mantenía con el Papa a causa de la potestad del "cuartel" de la sede diplomática, así como la espadaña y las distintas chimeneas que poblaban el tejado, tal vez con el deseo de dotar al edificio de mayor magnificencia.

En el plano del entrepiso (fig. 7) se localizaban los aposentos de parte del personal de la embajada, como el del capellán y el del maestro de ceremonias, así como la oficina de la contaduría ${ }^{53}$.

${ }^{53}$ AGA, AE, planeros, caja 54/261, documento 1, plano 4. Transcripción de la leyenda: "Indice de esta planta que es de diversos entresuelos para uso de la familia, y están entre el quarto vajo, y pr[incip]âl. N. ${ }^{\circ}$ II. 1. Escalera principal, y zaguan cubierto de d[ic]ho. Palacio expresado en la Planta del Quarto vajo, el qual con su altura llega asta el Quarto pr[incip]âl. y supera el presente de entresuelos. 2. Patio principal expresado en la planta del quarto vajo. 3. Cavalleriza grande de cavallos de respeto $\mathrm{q}[\mathrm{u}]^{\mathrm{e}}$ con su altura llega justam[en $]^{\text {te }}$ devajo del quarto pr[incip]âl expresada en la Planta del Quarto vajo. 4. Patio chico espresado en $\mathrm{d}[$ ic]ha Planta del Quarto vajo. 5. Otro patio assimismo expresado en la $\mathrm{d}[$ ic]ha planta. 6. Escalera principal. 7. Piezas de paso a las siguientes oficinas, y quarteles. 8. Aparador. 9. Quarteles de tres pieza, y un quartito para la familia. 10. Otro quartel de tres piezas $\mathrm{p}[\mathrm{ar}]$. $^{\mathrm{a}}$ la misma familia. 11. Escalera secreta que conduce a los Quartos principales. 12. Piezas de passo. 13. Otro quartel de quatro piezas $\mathrm{q}[\mathrm{u}]^{\mathrm{e}}$ puede darse (dividiendole) a dos criados. 14. Corredor $\mathrm{q}[\mathrm{u}]^{\mathrm{e}}$ conduce a diversos Quarteles, ó Aposentos. 15. Quartel de tres piezas p[ar]. ${ }^{\mathrm{a}}$ la familia. 16. Otro quartel de tres piezas $\mathrm{p}[\mathrm{ar}] .^{\mathrm{a}}$ la misma familia. 17. Escalera $\mathrm{q}[\mathrm{u}]^{\mathrm{e}}$ conduce al d[ic]ho Quartel n. ${ }^{\circ} 16$, y a los sig[uien $]^{\text {tes }}$ quartos chicos. 18. Dos quartos pequeños $\mathrm{p}[\mathrm{ar}]{ }^{\mathrm{a}}$ diversos usos. 19. Avitacion sobre la tienda $\mathrm{p}$ [ar]. a el armero del R[ea] ${ }^{1}$ Palacio. 20. Cochera expresada en la planta del Quarto vajo; cuia altura llega asta el piso del Quarto principal. 21. Escalerilla que conduce a las siguientes piezas de comodidad. 22. Guadarnes. 23. Aposentos del Archivero del R[ea] $]^{1}$ Palacio. 24. Escalerilla que de d[ic]ho. aposento subía al quarto pr[incip]âl y oy está condenada. 25. Trampa con puerta levadiza $\mathrm{p}[\mathrm{o}]^{\mathrm{r}} \mathrm{la} \mathrm{q}[\mathrm{u}]^{\mathrm{e}}$ se vaja a la escalerilla secreta, ya expresada en la planta del quarto vajo n. ${ }^{\circ}$ 15. 26. Contaduria. 27. Escalerilla $\mathrm{q}[\mathrm{u}]^{\mathrm{e}}$ conduce a los siguientes aposentos. 28. Aposento de siete piezas, y un 
La Pianta del Piano Nobile (fig. 5), de enorme interés por ser la más antigua del edificio que se conserva, albergaba las estancias de representación ${ }^{54}$. Se accedía a ella a través de la escalera diseñada por Borromini, que desembocaba en el vestíbulo remodelado por Antonio Canevari en 1726 , donde se encontraban otra pequeña escalera de acceso al piso superior ${ }^{55}$ y la portada de ingreso que daba paso a la "Sala Principal" ${ }^{\text {, }}$ muy importante para el ceremonial de recepción de la embajada ${ }^{57}$. Desde ella, a su vez, se accedía a las antecámaras de los cuartos de invierno y de verano, compuestos por distintas estancias en donde se celebraban reuniones y actos públicos, así como al dormitorio del embajador y sus retrocámaras anejas ${ }^{58}$. Dispuestas en enfilada, estaban dotadas de gran altura, como puede verse en la sección del edificio (fig. 6) ${ }^{59}$. Asimismo, desde las estancias de los extremos de la fachada era posible acceder a los balcones corridos de madera destinados a facilitar la contemplación de los festejos y ceremonias celebrados en la Plaza de España.

En el ala oeste del piano nobile se situaban la secretaría regia, la capilla, el dormitorio de invierno del embajador, "un gavinete de particular gusto, compuesto de porzelana fina de la china" anejo a dicha estancia decorado con piezas propiedad de Acquaviva (sala 14), cinco antecámaras

corredor, que se puede dividir para dos personas, devajo del qual queda otro piso de entresuelos, ademas de la comodidad del quarto vajo como se a expresado en el mismo Plano; a cuios entresuelos se vaja $\mathrm{p}[\mathrm{o}]^{\mathrm{r}}$ la escalera señalada en esta planta $\mathrm{n}^{\circ}{ }^{\mathrm{o}} 27$, y por la siguiente. 29. Escalera de madera que vaja a los $\mathrm{d}[\mathrm{ic}]$ hos entresuelos. 30 . Escalera secreta del Palacio $\mathrm{q}[\mathrm{u}]^{\mathrm{e}}$ conduce tambien al Aposento señalado ${ }^{\circ}{ }^{\circ}$ 28. 31. Corredor $\mathrm{q}[\mathrm{u}]^{\mathrm{e}}$ conduce al siguiente aposento. 32. Otro aposento de quatro piezas para familia. 33. Escalerilla secreta que del Quarto principal conduce al pasillo, y jardin expresado en la Planta del Quarto vajo; cuias paredes estan con la aguada mas clara, y otras semejantes para indicar que son mas vajas del presente plano".

${ }^{54}$ AGA, AE, planeros, caja 54/261, documento 1, plano 5. Transcripción de la leyenda: "Indice de esta Planta, que es del Quarto principal del Real Palacio de España que está en Roma. N. ${ }^{\circ}$ III. 1. Escalera principal. 2. Vestibulo, o desembarco de la escalera. 3. Escalerilla obalada $\mathrm{q}[\mathrm{u}]^{\mathrm{e}}$ conduce al quarto segundo. 4. Sala principal. 5. Ocho ante camaras del Quarto de verano. 6. Sala de dormitorio. 7. Dos salas interiores de $d[i c]$ ho Quarto. 8. Escalera secreta del mismo Quarto. 9. Guardaropa p[ar]. ${ }^{a}$ las libreas de lacaios. 10. Aposento, para huespedes, sobre él qual ai otro semejante, por ser este de menor altura de las piezas contiguas como por el corte se demuestra; al que se sube $\mathrm{p}[\mathrm{o}]^{\mathrm{r}}$ la escalerilla obalada señalada $\mathrm{n}^{\mathrm{o}} 3, \mathrm{y} \mathrm{p}[\mathrm{o}]^{\mathrm{r}}$ la siguiente. 11. Escalerilla de madera que sube a los $\mathrm{d}[\mathrm{ic}] \mathrm{hos}$ entresuelos. 12. Cinco antecamaras del quarto de inbierno. 13. Dormitorio. 14. Sala interior de dho quarto. 15. Gavinete. 16. Retrete. 17. Escalera secreta de d[ic]ho. Quarto. 18. Dos piezas interiores p[ar]. ${ }^{a}$ la servidumbre del mismo quarto. 19. Capilla. 20. Pequeña sacristia. 21. Patiecillo alto $\mathrm{q}[\mathrm{u}]^{\mathrm{e}}$ da luz a la d[ic]ha capilla. 22. Pasillo $\mathrm{q}[\mathrm{u}]^{\mathrm{e}}$ conduce a la primera antecamara del $\mathrm{Q}[\mathrm{uarto}]^{\text {to }}$ de Inbierno. 23. Secretaria regia. 24. Pasillo $\mathrm{q}[\mathrm{u}]^{\mathrm{e}}$ comunica de la primera antecamara del Quarto de Inbierno al Vestibulo q[u] está delante de la sala. 25. Terrado, o zutéa, $\mathrm{q}[\mathrm{u}]^{\mathrm{e}}$ corresponde a la calle Fratina. 26. Otro terrado. 27. Salon de Audiencia. 28. Theatro $\mathrm{p}[\mathrm{ar}]$. $^{\mathrm{a}}$ las serenatas, con balcon corrido alrededor, al $\mathrm{q}[\mathrm{ua}]^{1}$ se sube $\mathrm{p}[\mathrm{o}]^{\mathrm{r}}$ las dos escalerillas señaladas $\mathrm{n}^{\circ} 8$ y 11.29 . Otra escalera secreta. 30. Dos pasillos que conducen del Salon de Audiencia, señalado n. ${ }^{\circ} 27$, a las dos escaleras señaladas 8 y 11 , por las quales la nobleza sube al balcon $\mathrm{q}[\mathrm{u}]^{\mathrm{e}}$ ay alrededor del theatro, y no queda obligada a pasar $\mathrm{p}[\mathrm{o}]^{\mathrm{r}}$ dentro de $\mathrm{d}[\mathrm{ic}]$ ho theatro al tiempo q[u] $]^{\mathrm{e}}$ se hacen las Serenatas".

${ }^{55} \mathrm{La}$ escalera de Canevari sustituyó a la de madera circular proyectada por Borromini. Los diseños se conservan en el AGS, M. P. y D., V-123 y 124. Sobre esta intervención, que se llegó a realizar tal y como demuestran los planos realizados por Fuga y Hermosilla en 1747, véase Anselmi, A., ob. cit., 2001, p. 58.

56 También obra de Canevari, el diseño se conserva en el AGS, M. P. y D., XXVI-121. Sobre este tema, AnselmI, A., ob. cit., 2001, p. 110.

57 A modo de ejemplo, sobre el protocolo y ceremonial que regía en el edificio durante la embajada del marqués de Castel Rodrigo (1632-1641), véase la "Relaçion de la forma en que los embax[ador] es entran en Roma y las cortesias que dan y reciven de toda la Corte". Archivo Histórico Nacional, Nobleza, Osuna, Cartas, leg. 7, doc. 10.

${ }_{58}$ Dado que desde comienzos del siglo XVIII el cargo de embajador había estado ocupado por cardenales, la distribución del piano nobile había recuperado la distribución con la que Borromini lo había diseñado para el conde de Oñate, prescindiendo del ala femenina que había tenido que habilitarse durante el siglo XVII, ante la llegada de embajadores casados.

${ }^{59}$ AGA, AE, planeros, caja 54/261, documento 1, plano 2.

AEA, LXXXI, 321, ENERO-MARZO 2008, 31-48, ISSN: 0004-0428 


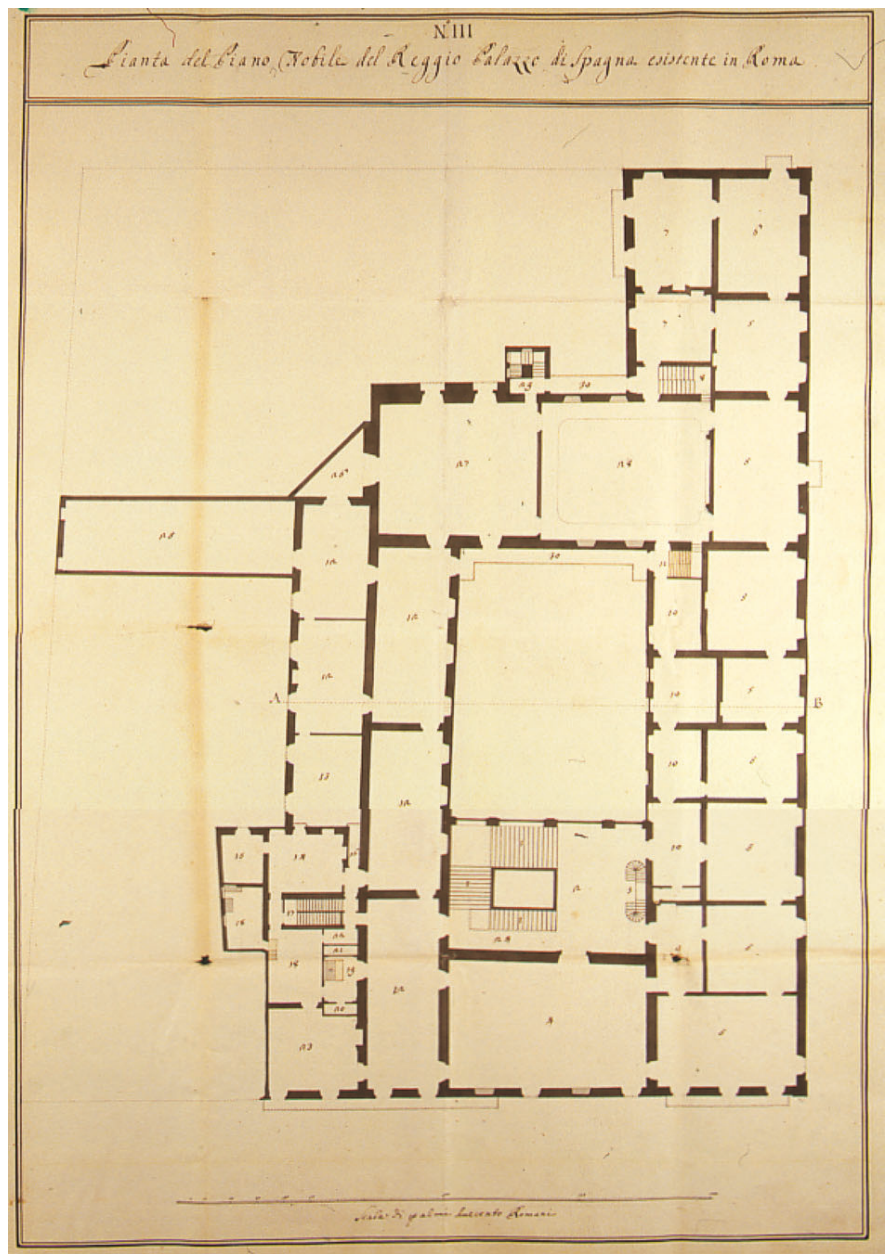

Fig. 5. Ferdinando Fuga y José de Hermosilla, N. III. Pianta del Piano Nobile del Reggio Palazzo di Spagna esistente in Roma, 1747. Archivo General de la Administración.

y el "terrado o azotea" descubierto construido por Antonio del Grande ${ }^{60}$. Por el contrario, en el ala este se ubicaba el cuarto de verano, formado por el dormitorio para el embajador, dos retrocámaras y ocho antecámaras, así como varios aposentos para huéspedes, estos últimos dotados de menor altura. Una de las antecámaras, aneja al teatro, se había habilitado como biblioteca, y en ella se custodiaban los libros adquiridos para la Academia de Historia Eclesiástica, otro de los proyectos puestos en marcha por Clemente de Aróstegui, cuyo fin era, al igual que habían hecho otras naciones europeas, "ilustrar, ya en general, ya en particular, la historia de sus Iglesias, de sus prelados, de sus concilios y de su disciplina" ${ }^{\prime \prime}$.

${ }^{60}$ La galería formaba parte de la ampliación del edificio realizada por Antonio del Grande en la segunda mitad del siglo XVIII. Entre 1785 y 1786 fue cubierta por el pensionista de arquitectura Ignacio Haan para instalar en ella las habitaciones del embajador José Nicolás de Azara. Sobre este tema, ANSELmi, A., ob. cit., 2001, pp. 82-83 y 113-114.

${ }^{61}$ En relación con la Academia de Historia Eclesiástica véase el impreso editado por Clemente de Aróstegui sobre sus objetivos y métodos, y los diarios manuscritos de las sesiones de la misma celebradas entre 1747 y 1748 (RBP, $\mathrm{VII} / 895)$. 


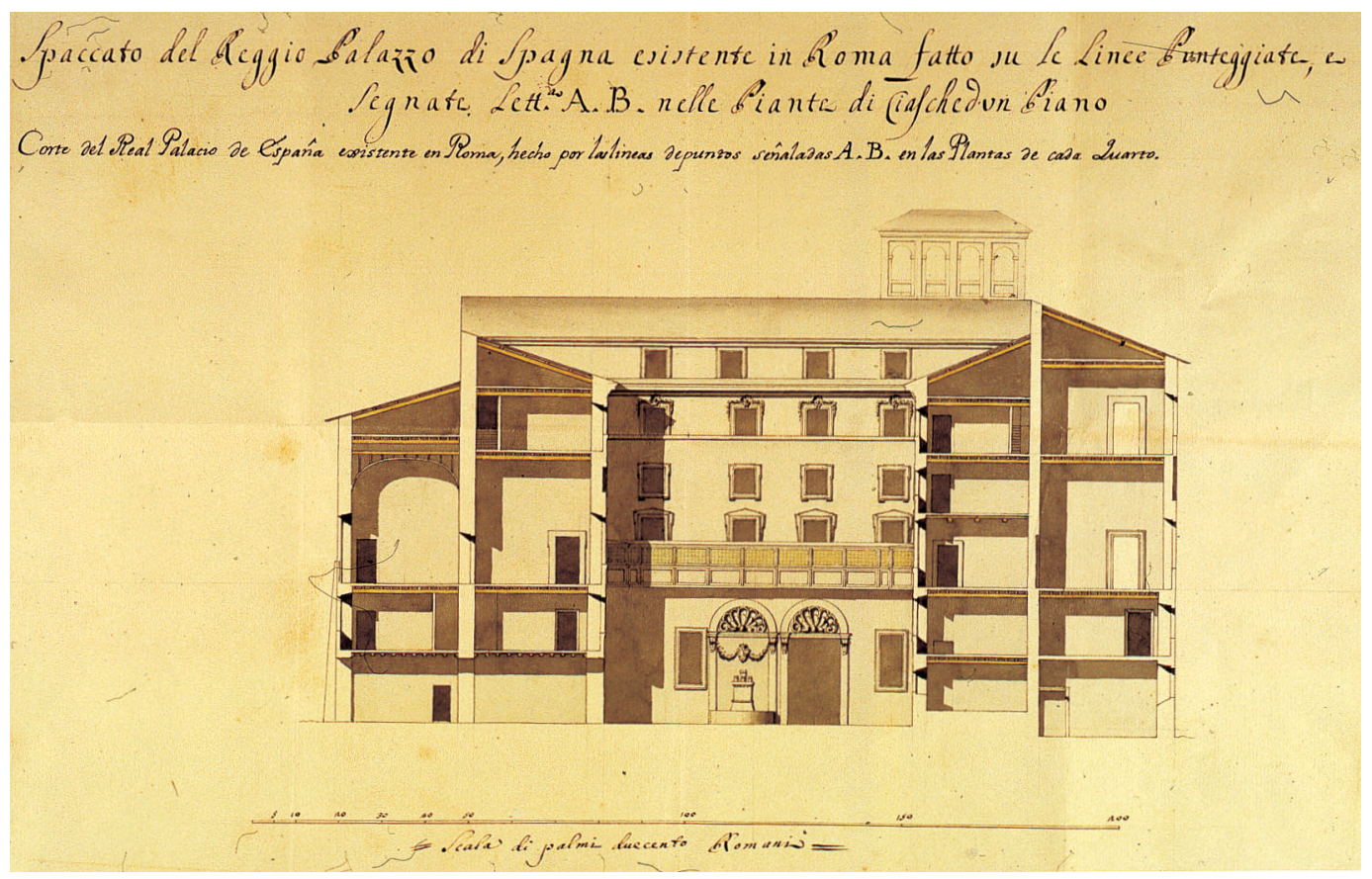

Fig. 6. Ferdinando Fuga y José de Hermosilla, Spaccato del Reggio Palazzo di Spagna esistente in Roma fatto su le linee punteggiate, e segnate lett A.B. nelle Piante di ciasched'un Piano, 1747. Archivo General de la Administración.

Las salas de aparato estaban situadas en la crujía norte que daba a la calle Mario de'Fiori. Allí se localizaban el Salón de la Audiencia, que en 1747 estaba aún adornado con las colgaduras de Acquaviva que Clemente de Aróstegui intentó comprar a Isabella de Acquaviva Strozzi62, y el teatro. Mandado construir por el cardenal en 1745, disponía de un palco corrido para el acomodo de los espectadores, al que se llegaba a través de dos escaleras (núms. 8 y 11). Ambas salas eran accesibles tanto desde las antecámaras anejas como desde un pasillo volado sobre el patio que permitía la circulación sin causar ninguna molestia "al tiempo q[ue] se hacen las cantatas".

62 Tras la muerte de Troiano Acquaviva su hermana, Isabella de Acquaviva Strozzi, procedió a sacar de la embajada los bienes del cardenal "para dexarlo libre, como lo deseaba Mons[eñ $]^{\text {or }}$ Clemente, a excepción de dos solas estancias; es a saber la camara de audiencia, adobada de terciopelo cremesi, con su dosel, y de un gavinete de particular gusto, compuesto de porzelana fina de la china". El contenido de ambas salas había sido inventariado y tasado por un perito en 2.645 y 1.590 escudos romanos respectivamente, si bien al cardenal le habían costado 7.000, tal y como figuraba en las cuentas originales en posesión de la heredera (Carta de Isabella de Acquaviva Strozzi a Joseph de Carvajal y Lancaster, Roma, 17 de agosto de 1747. AGA, AE, caja 54/261). Finalmente, en noviembre Clemente de Aróstegui escribió a Carvajal recomendando la compra de las colgaduras y muebles de la cámara de audiencia (dos sillas, cinco arañas de 16 luces, "dos mesas de piedra esquisita con sus pies de madera dorada de bellisima labor, y entallo" y distintos tejidos y colgaduras), mientras que respecto al contenido del gabinete, del que remitía inventario, "no lo contemplo tan necesario, asi por ser estas muy comunes y no haver ninguna exquisita, como por que con el tiempo las quitarian a poco a poco". Carta autógrafa de A. Clemente de Aróstegui a Joseph de Carvajal y Lancaster. Roma, 30 de noviembre de 1747, AGA, AE, caja 54/261. 


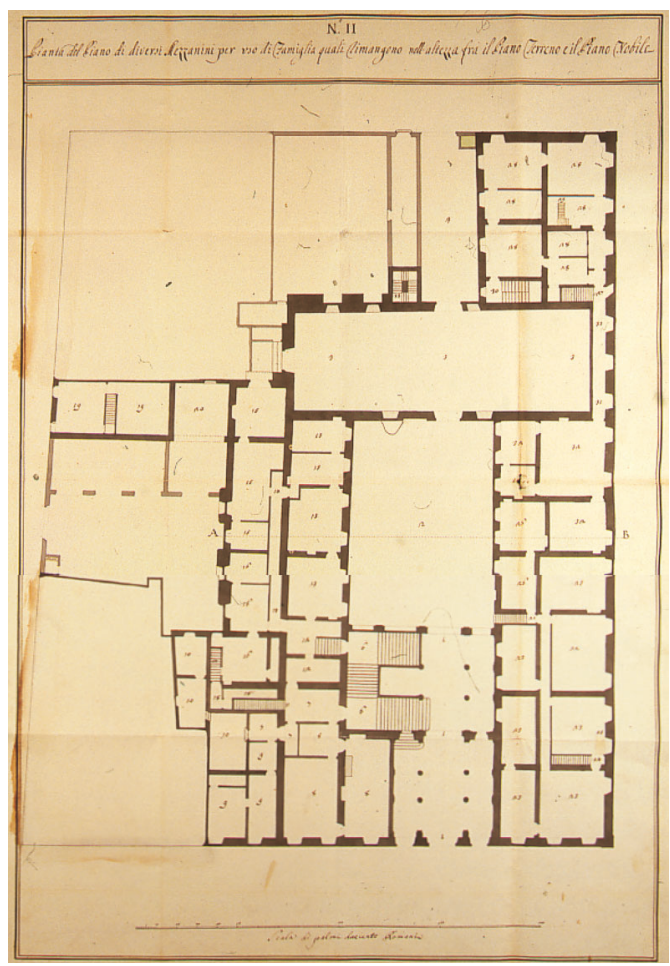

Fig. 7. Ferdinando Fuga y José de Hermosilla, N. II. Pianta del Piano di diversi mezzanini per uso di Famiglia quali rimangono nell'altezza fra il Piano Terreno e il Piano Nobile, 1747.

Archivo General de la Administración.

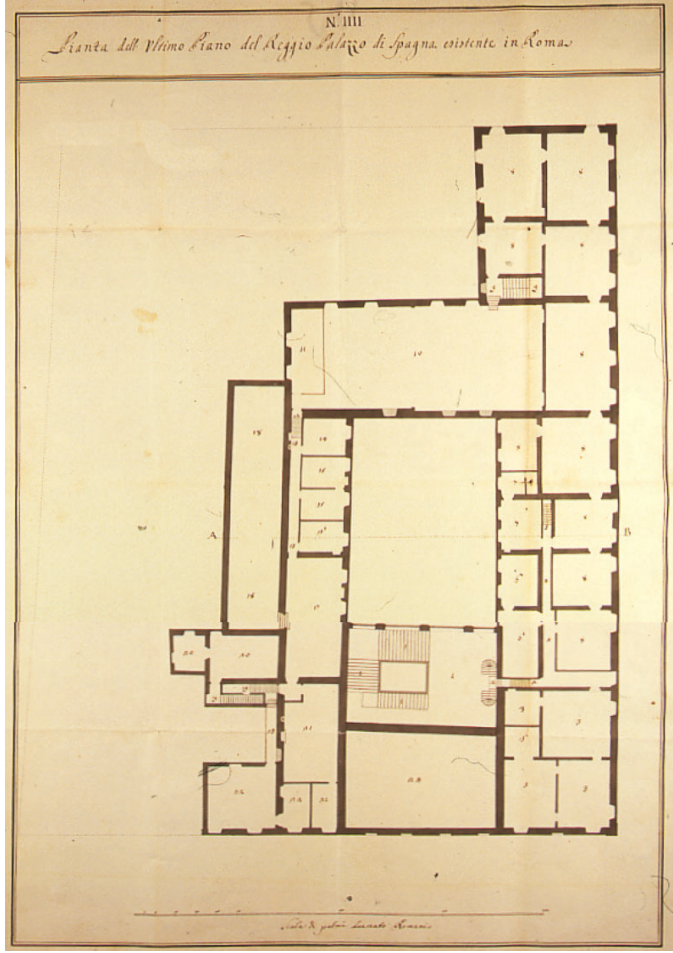

Fig. 8. Ferdinando Fuga y José de Hermosilla, N. IIII. Pianta dell'ultimo Piano del Reggio Palazzo di Spagna esistente in Roma, 1747. Archivo General de la Administración.

Gracias a la sección del edificio (fig. 7), que muestra las cuatro plantas del palacio y el modo en que se cubrían sus distintas estancias, podemos constatar la mayor altura de las salas del piano nobile, cuyas puertas estaban decoradas con molduras, así como la presencia del corredor construido para comunicar el ala de invierno y de verano sin tener que pasar por el salón de audiencia y el teatro. En lo que respecta a la articulación y decoración del patio, realizada bajo la dirección del arquitecto Giovanni Domenico Pioselli en la década de $1690^{63}$, a mediados del siglo XVIII presentaba un estado que, salvando pequeños detalles como el actual enlucido que recubre los muros o la fuente, se ha mantenido hasta nuestros días.

Finalmente, en el último piso (fig. 8) se ubicaban distintas habitaciones privadas del personal de la embajada, así como la armería, el archivo y la imprenta ${ }^{64}$.

${ }^{63}$ Anselmi, A., ob. cit., 2001, p. 99.

${ }^{64}$ AGA, AE, planeros, caja 54/261, documento 1, plano 6. Transcripción de la leyenda: "Indice de la Planta del Quarto segundo, y ultimo del Real Palacio de España que está en Roma. N. ${ }^{\circ}$ IIII. 1-Escalera principal expresada en la Planta del Quarto principal, y por q[u $]^{\mathrm{e}}$ termina en el, se a dado la aguada (en esta planta) mas clara. 2. Una de las escalerillas $\mathrm{q}[\mathrm{u}]^{\mathrm{e}}$ conduce al presenta plano. 3. Aposentos para familia noble, con cinco piezas. 4. Corredor que conduce a otros Aposentos. 5. Escalerita de madera $\mathrm{q}[\mathrm{u}]^{\mathrm{e}}$ conduce a los desbanes. 6. Aposento para familia con cinco piezas. 7. Otro aposento para familia, de dos piezas y un quartito. 8. Nueve piezas que constituien un aposento noble al qual 


\section{La autoría de los dibujos: Ferdinando Fuga y José de Hermosilla}

Debido a que los planos no están firmados, gracias al tipo de dibujo acabado, al uso de tinta gris con ligeras aguadas en verde y amarillo, al sistema de numeración empleado, las extensas leyendas que los acompañan y al papel verjurado en el que fueron realizados, podemos atribuirlos a Ferdinando Fuga ${ }^{65}$, buen conocedor del edificio y su entorno ${ }^{66}$. Sin embargo, el tipo de escritura de las distintas anotaciones denota la participación de otro arquitecto de su estudio en la realización de los seis planos de la embajada.

En el caso de las inscripciones en castellano, la caligrafía nos permite identificar a uno de esos ayudantes con el pensionado José de Hermosilla, quien desde su llegada a Roma se encontraba bajo las enseñanzas del arquitecto florentino ${ }^{67}$. La carta de Clemente de Aróstegui con la que comenzábamos este trabajo informando de que "el diseño de n[uest]ro Palacio q me hizo Hermosilla en Roma, no me lo han devuelto los Reyes, y se lo tienen en la Sala de la Conversacion [del palacio del Buen Retiro]. Lo siento, y me complazco" ratifica esta hipótesis $^{68}$, si bien plantea el interrogante de por qué el antiguo embajador en Roma, seis años después de la realización de los planos, había "olvidado" la participación de Ferdinando Fuga como director del proyecto, y lo atribuía íntegramente al -por entonces- director de arquitectura de la Real Academia de Bellas Artes de San Fernando, institución de la que él mismo era viceprotector.

Entre 1747 y 1751 José de Hermosilla y Sandoval (1715-1776) había disfrutado de una estancia de estudio en Roma en calidad de pensionado de la Junta Preparatoria tras sustituir a Diego de Villanueva -ganador efectivo de la plaza por oposición- gracias a la influencia de Joseph de Carvajal y Lancaster, Ministro de Estado y protector de la Academia entre 1746 y 1754, y a la de su hermano Ignacio Hermosilla, secretario de dicha institución ${ }^{69}$.

A su llegada a la Ciudad Eterna el embajador Clemente de Aróstegui le puso "para que prosiga sus estudios de Arquitectura con el Cavallero Fuga, que es uno de los Maestros más

se puede subir por la siguiente escalera, ademas de la señalada n. ${ }^{\circ}$ 2. 9. Escalera secreta de $d[i c]$ ho Palacio, expresada tambien en los planos de abajo. 10. Guardaropa. 11.Pieza para el guardaropa. 12. Escalerilla $\mathrm{q}[\mathrm{u}]^{\mathrm{e}}$ conduce a dha guardaropa. 13. Corredor que sirve a las siguientes piezas. 14. Pieza $\mathrm{p}[\mathrm{ar}]{ }^{\mathrm{a}}$ los criados menores. 15. Dos piezas para los mismos. 16. Otra camara p[ar]. ${ }^{a}$ los criados. 17. Salon de Paso. 18. Desban grande. 19. Otra escalerilla que sirve a las $\mathrm{d}[\mathrm{ic}]$ has avitaciones, y a los siguientes aposentos y comodidades. 20. Archivo. 21. Armeria. 22. Aposento para criados maiores, de dos piezas. 23. Pasillo que de $\mathrm{d}[\mathrm{ic}]$ ho aposento va a las escalera señalada $\mathrm{n} .{ }^{\circ} 19.24$. Vano de la sala del quarto principal, cuia elevación compreende el presente quarto".

${ }^{65}$ La filigrana del papel verjurado utilizado para la realización de los seis dibujos de la embajada coincide con el empleado por Fuga en distintos proyectos de las décadas de 1740 y 1750 Sobre este tema, Mongini Tella, M. P. y Lanfiuti Baldi, R., "Filigrane", en Kieven, E., ob. cit., 1988, pp. 295-301.

${ }^{66}$ En 1745 Fuga había propuesto construir una iglesia en la Plaza de España con el objetivo de reafirmar la jurisdicción de la embajada. Anselmi, A., ob. cit., 2001, p. 188.

${ }^{67}$ Para una comparación de la caligrafía, véanse los dibujos de Hermosilla contenidos en su tratado sobre Arquitectura civil y los que realizó para las Antiguedades árabes de Granada. Sobre este último, RodríGuez RuIZ, D., La memoria frágil. José de Hermosilla y las Antigüedades Arabes de España, Madrid, 1992.

${ }^{68}$ Carta de Clemente de Aróstegui, correspondencia reservada. s.f. [finales septiembre-principios octubre de 1753]. AGS, E, leg. 5.857, doc. 75, citada en RodríGuez Ruiz, D., ob. cit., 1985, p. 70.

${ }^{69}$ Sobre la figura del arquitecto véase SAMBRicio, C., "José de Hermosilla y el ideal historicista en al arquitectura de la Ilustración”, Goya, núm. 159, 1980, pp. 140-151; Rodríguez RuIz, D., ob. cit., 1992; Rodríguez RuIz, D. y SAMBRICIO, C., "El conde de Aranda y la arquitectura española de la Ilustración", en FERrER BENIMELI, J. A. (com.), El conde de Aranda, Zaragoza, 1998, pp. 149-171; Rodríguez Ruiz, D., "La sombra de un edificio. El Escorial en la cultura arquitectónica española durante la época de los primeros Borbones (1700-1770)", Quintana, núm. 2, 2003, pp. 57-94. Respecto a su estancia en Roma y los contactos que estableció, DeuPI, V. L., Architectural temperance: Spaniard and Rome, 1700-1758, Tesis Doctoral Inédita, Universidad de Pennsylvania, 1999. 
célebres de Italia" ${ }^{70}$. Además el joven español también mantuvo importantes contactos con los pensionados de la Academia de Francia, con el círculo científico e intelectual de Giambattista Nolli y con los debates que se mantenían en la Accademia di San Luca, los cuales le debieron resultar bastantes cercanos tras su etapa como delineador en el Palacio Real de Madrid bajo las órdenes de Sacchetti.

En la ciudad de los Papas, además de estudiar de modo riguroso los textos más importantes de la cultura arquitectónica y los principales repertorios de grabados de la arquitectura antigua y moderna, participó en algunas construcciones, como la conclusión de la iglesia de la Trinidad en via Condotti, y en la elaboración de un proyecto de "máquina para limpiar puertos".

Asimismo, y gracias a su sólida formación, poco frecuente entre los arquitectos españoles del momento -fruto de los estudios de filosofía y teología que había cursado en Sevilla, y de su condición de ingeniero militar y delineador del Palacio Real de Madrid desde 1745- durante su estancia en Roma redactó un tratado sobre Architectura Civil, verdadera síntesis de la cultura arquitectónica internacional de la Roma de la década de 1740, que debía servir de base al nunca realizado curso de arquitectura para la Junta Preparatoria y que convirtió a Hermosilla, junto con Ventura Rodríguez y Diego de Villanueva, en uno de los arquitectos que contribuyeron a la configuración de la enseñanza de la arquitectura en la Real Academia de San Fernando ${ }^{71}$.

En 1751, coincidiendo con la partida de Ferdinando Fuga de Roma a Nápoles para trabajar en el proyecto del Albergo dei Poveri, Hermosilla recibió la orden de la Junta Preparatoria de la Academia de regresar a Madrid, por considerar que ya había realizado suficientes progresos en sus estudios.

Sirva la presentación de estos planos del Palacio de España en Roma en los que colaboró José de Hermosilla bajo las órdenes de Fuga para dar un paso más en el conocimiento de la estancia italiana del arquitecto español.

Fecha de recepción: 23-III-2007

Fecha de aceptación: 24-VI-2007

\footnotetext{
${ }^{70}$ Archivo de la Real Academia de Bellas Artes de San Fernando, leg. 3-18/1, citado en MoleÓn, P., ob. cit., 2003, p. 89 .

71 Sobre el tratado, conservado en la Biblioteca Nacional de Madrid, mss. 7.573, véase RodríGuEz RuIZ, D., ob. cit., 1985; Idem, ob. cit., 2002; Idem, "La arquitectura cortesana y los sitios reales", en SANTiAgO PÁEz, E. (dir.), La Real Biblioteca Pública, 1711-1760. De Felipe V a Fernando VI, Madrid, 2004, pp. 433-436, y la edición crítica de dicho tratado realizada por Delfín Rodríguez Ruiz (en prensa).
} 